$\xi=$ 离

\title{
Methodology utilized in the socio-economic determinants of adolescent pregnancy in Katutura, Windhoek: Namibia
}

\author{
Taimi Amakali-Nauiseb *, Susie-Ubomba Jaswa \\ School of Nursing, School of Public Health \\ University of Namibia, University of Limpopo \\ *Corresponding author E-mail: tnauiseb@unam.na
}

\begin{abstract}
This study focuses on the methodology utilized in the study of the socio-economic determinants of adolescent pregnancy in Katutura, Windhoek: Namibia. The following aspects were explained, processed and methods use to conduct the study, the framework of the study, the procedures in selecting the participants and setting of the interviews. The aim of this study was to collect detailed information to explore the socio-economic determinants of adolescent pregnancy in Katutura, Windhoek: Namibia.

The clinical study was a descriptive, cross-sectional study of three months duration. Semi-structured interviews methods were utilized to collect the data. A random sampling method was use to select the participant e.g. every second pregnant adolescent was interviewed. The interviews were done on specific days, Mondays and Thursdays, which were the follow-up days for antenatal clinic. Study participants were selected from a population of pregnant women attending the Katutura antenatal clinic. Inclusion and exclusion criteria were adhered in the selection process. Study population was all pregnant women attending the Katutura antenatal clinic during the time of the study. The study sample of 150 pregnant adolescent were accepted into the study. Data analysis; mixed methods analysis was used to interpret the data.

Based on some the findings of the study $89 \%$ of the pregnant adolescent falls between the ages 17-21 who visited the ante -natal clinic. The majority interviewed represents $65 \%$ of the highest-grade completed grade $8-10$. The mean age of the first intercourse is 16.5 years.
\end{abstract}

Keywords: Adolescence; Adoption; Contraception; Emotional Support; Financial Support.

\section{Introduction}

The article was extracted from the authors study "Socio-economic determinants of adolescent pregnancy in Katutura, Windhoek: Namibia".

This study focuses on the methodology utilized in the study of the socio-economic determinants of adolescent pregnancy in Katutura, Windhoek: Namibia. The following aspects were explained, processed and methods use to conduct the study, the framework of the study, the procedures in selecting the participants and setting of the interviews.

According to Namibia Demographic Health Survey (NDHS 2003, NDHS 2013) early childbearing particularly among teenagers (those under 20 years of age) has detrimental demographic, socioeconomic and socio-cultural consequences. Teenage mothers are more likely to suffer from complications during delivery, which result in higher morbidity and mortality for both themselves and their children. In addition, the socio-economic advancement of teenage mothers in the areas of educational attainment and accessibility to job opportunities may be curtailed. A study conducted by Mostert (1988) found that 80 percent of the females in Katutura had their baby in their teens.

Namibia is no exemption to the problem of teenage pregnancy. Both the report of NDHS (2006, 2007, 2013) and USAID (2011) indicate that the rate of teenage pregnancy in Namibia stand at $15.4 \%$ and $15 \%$ respectively. Teenage pregnancy appears unwanted because it is unplanned. Unplanned teenage pregnancy is often terminated by abortion, a negative experience that may have a lifelong emotional and social impact on her.

Adolescent pregnancy is not a new phenomenon in Namibia. Few surveys have been conducted to assess this problem. Nevertheless the UNICEF Survey (HHS, 1990) (NDHS, 2013) indicated that more than $50 \%$ of women have had their first child during their teens, and the mean age of this group for the first birth was 16.3 years.

As stated by Lillian \& Mumbango, 2015 adolescent pregnancy is not a new issue in Namibia. There have been always young women, their partners and their family facing difficult life changing decisions because of intended or unintended pregnancy. Until recently, adolescent pregnancy was considered a private matter that involved the pregnant adolescent and the immediate family members. This issue has now however become a public concern. According to NDHS $(2003,2013)$ the women age 15-19 years who are already mothers or pregnant; about one in seven adolescent women (15 percent) in Namibia is already a mother and another 3 percent are pregnant with their first child. Thus, 18 percent of adolescent women have begun the childbearing.

As indicated in the study by Omar, Hasim, Muhammad, Jaffar, Hashim \& Siraj ( 2010) there were significant associations between adolescent pregnancy and low education level, low socioeconomic status, being raised by a single parent, not engaging in extra-curricular school activities, engaging in unsupervised activities with peers after school, and substance abuse being anemic, being unsure of the expected delivery date (Omar et al.2010).

In Namibia, we increasingly witness a distressing phenomenon: babies having babies. Namibia's teenage mothers are among the 
vulnerable groups in society. The rate of teenage pregnancy is high. According to the Demographic and Health Survey of 1993, by age 19 , approximately $45 \%$ of all girls have already started child bearing. In the north-east the figure is as high as $75 \%$. Countrywide, $22 \%$ of the girls in the age group 15-19 are mothers (NDHS 2003, NDHS 2013).

Likewise the Ministry of Education reported 3039 schoolgirls in Ondangwa region who fell pregnant in 1992 and in one school in Katutura 22 girls had fallen pregnant between January and August 1992 (Hailonga, 1993).

As indicated by the World Health Organization, Adolescent: refers to young people age 15-19 and Adolescent pregnancy is pregnancy in girls aged 15-19 years of age.

The notion of adolescent is defined as an "era" in the historical sense. It is a period extending from an epoch and characterized especially by a new order of things (International Encyclopedia of the Social Sciences, 1968). Here the epoch, defined as the starting point of a new period, especially as marked by striking event is puberty. Puberty is characterized by biological events that signal the initiation of sequence of biochemical, physiological, physical transformation of child into adult.

Clearly a number of factors could be responsible for these sexual activities that need urgent attention in order to reduce the number of teenagers who are getting pregnant. Since little or no attention is given to these practices and beliefs with regards to sexual activities in teenagers (in Namibian society) there is no doubt that they need to be looked into. It is therefore imperative that in order to expect improvement in the sexual behavior among teenagers, strategies must be developed to control the responsible factors (Hailonga, 1993).

Windhoek, as the capital and largest urban center, has attracted people from all over the country, and Windhoek's African Township, Katutura has experienced significant urban migration in recent years. The people come from a diversity of backgrounds and they have been influenced by a variety of forces of change (Pendleton, 1996).

The population of Windhoek in 2011 was 325,858 , growing continually due to an influx from all over Namibia (https://en.wikipedia.org/wiki/Windhoek).

The study was conducted in Katutura; a black township outside Windhoek. The population in this area is predominantly black, consisting of people from all different ethnic groups. It is estimated that nearly 195514 people live in this area; of this 34 percent are children of sixteen years of age and younger. The population in this area is a result of migration from rural areas. Migrant's account for the $81 \%$ of the adult population (Pendleton, 1994).

According to UNICEF Report (2008), women below 20 are likely to experience maternal death four times more than women above the age of 20. Adolescent childbearing, common in many parts of the world, carries particular risks.

"Unprotected sex by adolescents consequently resulted in pregnancies, which may lead to their dropping out of school, marrying early, abandoning babies and obtaining illegal abortion". Adolescents who engage in unprotected sex are likely to be infected with HIV and AIDS as well as other STD's.

Whether or not a young mother of 16 or 19 years is seen as a problem case largely depends on the society in which she lives. The perception varies with the socio-economic context and the congruent concept of youth in general and young women in particularly. There are many reasons why adolescent motherhood is cause of distress.

Among them are genuine concerns about the medical risks associated with early pregnancy and about the consequences for mother and child. However, there is also 'the moral panic' aroused by youthful sexuality and the ambiguity of adolescence as a status. It cannot be denied that there are good social reasons for delaying maternity. Trying to provide girls with an education and opportunities for good jobs are certainly valuable objectives in presentday Namibia.

On the other hand, for women to begin childbearing relatively late during their reproductive years, is only valid in society where formal education and employment opportunities determine, to a larger extent, the prospects individuals and their families have in life (Mogotsi, 1998).

In Namibia the prevalence of adolescent pregnancy was $31.3 \%$; and as stated by Lillian \& Mumbango 2015, adolescent pregnancy was influenced by generation, region, highest educational level, socio-economic status and cultural factors. Intervention programs and policy initiatives should focus on youth, regions, everyone regardless of the socio-economic or culture.

\section{Aim and objectives of the study}

\subsection{Aim of the study}

The aim of the study was to explore the data collection methods utilized in the investigation of socio-economic determinants of adolescent pregnancy in Katutura, Windhoek: Namibia. In order to obtain information that would be useful in identifying the kinds of problems adolescents faced in order to design programs that will meet their needs with regard to sexual matters.

\subsection{Research objectives}

- To identify and highlight the contributing factors to adolescent pregnancy.

- To find out the reasons why adolescent pregnancy is on the increase.

- To explore the knowledge of adolescents on safe sex practices and HIV/AIDS.

- To establish/investigate the knowledge of adolescent on contraceptive methods.

\section{Methods}

\subsection{Study design}

The clinical study was a descriptive, cross-sectional study of three months duration. Study participants were selected from a population of pregnant adolescent women attending the Katutura antenatal clinic.

A random sampling method was use to select the participant e.g. every second pregnant adolescent was interviewed. The study utilized quantitative research methods. Inclusion and exclusion criteria were adhered too. The data was collected through semistructured interviews with a total of 150 pregnant adolescents interviewed in Katutura, Windhoek, between the ages of 12 to 21 years.

\subsection{Study population}

All pregnant adolescents' women who attended the Katutura antenatal clinic during the time of the study were included.

\subsection{Study sample}

One hundred and fifty pregnant adolescent were accepted into the study.

\subsection{Inclusion and exclusion criteria}

For inclusion into the study the participants were required to:

- Be a pregnant adolescent.

- Be between the ages 12 to 21 years.

- Attend Katutura antenatal clinic.

- Give informed consent.

Participants were excluded from the study on the basis of the following:

- Not pregnant adolescent

- Younger than 12 years. 
- Older than 21 years.

\section{Methods and assessment}

\subsection{Structured interviews.}

Since the aim of the study was to collect detailed information, the researcher used the semi-structured interviews methods to collect the data. Semi-structured interviews are open-ended questions that enable the researcher to gain detailed understanding of a respondent's perception of a particular topic (Smith 1995, Brink 2012). It is flexible as it allows the researcher to seek elaboration and clarification on important themes that emerge from an interview. The informant is also able to give a fuller understanding and perception of a topic (Smith 1995, Brink 2012).

The interviews were conducted on specific days, on Mondays and Thursdays, which were the follow-up days for antenatal clinic. At the beginning of the interview the researcher welcomes and thanked the participant individually for volunteering to participate. The researcher introduced her and explained the purpose of the study and interview to ensure that there was no confusion. An explanation was also given regarding the process of the interview. The researcher further explained the confidential manner in which the interview will be treated and that anonymity will be ensured, no need for identification by name during the interview. The researcher carried out the interview in the following languages, English, Afrikaans and Oshiwambo.

A random sampling method was use to select the participant e.g. every second pregnant adolescent was interviewed.

\section{Data analysis}

Qualitative and Quantitative thematically analysis was used to interpret the data. It is however important that researchers give meaning to the participant's interview and engage in an "interpretative relationship with the transcription" (Smith 1995, Brink 2012).

Themes are seen as "...abstract constructs investigators identify before, during and after data collection" (Ryan \& Bernard 2000, Brink 2012).

After the data collection process was completed, the participants were thanked and given health education on postnatal care and the use of contraceptives method.

\section{Permission of the study}

Prior to the start of the investigation, a protocol was submitted to the committee for research of the National School of Public Health, Medunsa, and Pretoria for approval. The protocol was approved.

Application was also submitted with the Ministry of Health and Social Services, through the permanent secretary's office and permission was granted.

The pilot study conducted at Windhoek Central hospital, antenatal clinic and the study were carried out at Katutura State hospital, antenatal clinic.

\section{Ethical aspects}

The pregnant adolescents participated voluntarily and were free to refuse to divulge certain information about them. The direct consent for participation was obtained from pregnant adolescents themselves and privacy was assured (Brink 2010, Brink 2012).

Anonymity was of great importance and pregnant adolescents were respected and requested not to write their names on the questionnaires (Brink 2010, Brink 2012).

Pregnant adolescents assured that all information to be kept confidential. Data used for the stated purpose and no other person to have access to interview data/information (Brink 2010, Brink 2012).

\section{Discussion}

\subsection{Results}

Data analysis; qualitative and quantitative thematically analysis was used to interpret the data.

\section{Conclusion}

The structured interview methodology provided us with the opportunity and the ability to truly understand adolescents' lives and problems experienced. Although, the importance exist of conducting the study in both the urban and rural setting to get a clear picture. After the data collection process was completed, the participants were thanked and given health education on postnatal care and the use of contraceptives method.

\section{Acknowledgement}

The study was conducted with the permission of the pregnant adolescents who agreed to participate in the study at Katutura antenatal care. God be with you all.

\section{References}

[1] Brink, H. (2010). Fundamentals of Research Methodology for Health Care Professional. CapeTown, Juta \& Co. (Pty) Ltd.

[2] Brink, H. (2012). Fundamentals of Research Methodology for Health Care Professional.CapeTown, Juta \& Co. (Pty) Ltd

[3] Department of Reproductive Health and Research World Health Organization. (2011) Adolescent Pregnancy. Avenue Appia 20, CH-1211 Geneva 27, Switzerland E-mail: reproductivehealth@who.int

[4] Hailonga, P. (1993). A Study to Identify Adolescents' Knowledge, Attitudes and Beliefs towards Teenage Pregnancy. Windhoek Printers, Namibia.

[5] https://en.wikipedia.org/wiki/Windhoek.

[6] International Encyclopedia of the Social Sciences. (1968) Vol.1.Sills (ed.). The Macmillan Company and the Free Press.

[7] Jagdeo T.P. (1984). Teenage Pregnancy in the Caribbean. International Planned Parenthood Federation, Western Hemisphere Region, New York, USA.

[8] Kozier, B. and Erb, G. (1987): Fundamentals of Nursing Concepts and Procedures. Addison-Wesley Publishing Company: California.

[9] Liang.e.1.m. (2013). Adolescent Pregnancy: A Review of the Evidence. UNFPA New York, 2013

[10] Lillian P, Mumbango T (2015) Statistical Modeling of Adolescent Pregnancy in Namibia. J Nurs Care 4: 262. Doi: Volume 4 • Issue 4 -10.4172/2167-1168.1000262.

[11] May, T. (1993). Social Research, Issues, Methods and Process, Buckingham: Open University Press.

[12] Mensah, E. (2002). Teenage Pregnancy and its Effect on a Girl Academic Progression in Kabakaba educational circuit in the Central Region.Ghana.

[13] Minnesota Department of Health. (2010). Adolescent Pregnancy Prevention Interventions.website:http://www.advocatesforyouth.org/storage/advfy/doc uments/sspregnancies.pdf.

[14] Ministry of Education and Culture. (2008). School Policy on Learner Pregnancy in Namibia: Summary of Background Information: Gender Research \& Advocacy Project Legal Assistance Centre

[15] Ministry of Health and Social Services. (2004) Adolescent Friendly Health Services Notes. Windhoek: Namibia.

[16] Ministry of Health and Social Services. (2002) Health Information Statistics. Windhoek: Namibia.

[17] Ministry of Health \& Social Services (MoHSS). (2013). Namibia Demographic Health Survey. Windhoek. Namibia.

[18] Ministry of Health \& Social Services (MoHSS). (2006/7). Namibia Demographic Health Survey Windhoek. Namibia. 
[19] Ministry of Health \& Social Services (MoHSS). (2003). Namibia Demographic Health Survey Windhoek. Namibia.

[20] Mogotsi, I. (1998). Formal Education and Pregnancy among Learners in Namibia. The Hague: Netherlands.

[21] Mwamwenda, T.S. (1990). Educational Psychology: An African Perspective. Butterworths Professional Publishers (Pty) Ltd: Durban.

[22] Omar, K., Hasim, S., Muhammad, N. A., Jaffar, A., Hashim, S. M. \& Siraj, H. H. (2010). Adolescent Pregnancy Outcomes and Risk Factors in Malaysia. https://doi.org/10.1016/j.ijgo.2010.06.023.

[23] Pendleton, W.C. (1994). Katutura A Place Where We Stay. Gamsberg Macmillan Publishers Pty) Ltd, Windhoek: Namibia.

[24] Pendleton, W.C. (1996). Katutura: A Place Where We Stay: Life in a Post-Apartheid Township in Namibia. Gamsberg Macmillan Publishers Pty) Ltd, Windhoek: Namibia.

[25] Ryan, G.N. \& Bernard, H.R. (2000). Data Management and Analysis Methods. In Denzin, N.K. \& Lincoln, Y.S. (Eds), Handbook of Qualitative Research $2^{\text {nd }}$ ed. USA: Sage Publication: 769-820.

[26] Republic of Namibia. (1995). Convention on The Elimination of all Forms of Discrimination against Women (CEDAW). First Country report. Department of Women's Affairs.

[27] Republic of Namibia. (1996). Family Planning Service Protocol for Operational Level Health Workers. Ministry of Health and Social Services. Government Printers.

[28] Republic of Namibia. (1993). Namibian Education, the Challenge of Undoing Apartheid. Ministry of Basic Education and Culture. Windhoek: Government Printers.

[29] Republic of Namibia. (1995). Policy Draft on Pregnancy among Learners in School. Ministry of Basic Education and Culture. Windhoek: Government

[30] Republic of Namibia. (1991). Proceedings of the National Safe Motherhood Conference Held in Windhoek.MOHSS, UNPF, UNICEF.Windhoek.

[31] Simon.K.(2013).Investigation of Teenage Pregnancy in Oshana Region.Namibia.

[32] Smith, J.A. (1995). Semi Structured Interviewing and Qualitative Analysis. In Smith, J.A.Horne, R \& Van Langenhove, L. (Eds), rethinking methods in psychology. London: Sage: 9-26.

[33] Saito.M.I (1998). Sex Education in School: Preventing unwanted Pregnancy in Adolescents.).December 1, 1998, Volume 63, Supplement 1, Pages S157-S160

[34] UNICEF, Namibia. (1990). Household and Nutrition Survey MoHSS, Windhoek: Namibia.

[35] United States Agency for International Development (USAID). (2011) Teenage Pregnancy in Kavango Region: Contributing Factors and Program Recommendation.

[36] Voeten, H. (1994). Teenage Pregnancy in Namibia. Department of Cultural Anthropology University of Utrecht: Netherlands.

[37] WHO (2014) .Adolescent Pregnancy Fact Sheet, Department of Reproductive Health and Research, Geneva, Switzerland. 